\title{
Microstructure Evolution during Tensile Deformation of a Nanostructured Bainitic Steel
}

\author{
S.S. Babu ${ }^{1}$, S. Vogel ${ }^{2}$, C. Garcia-Mateo ${ }^{3}$, B. Clausen ${ }^{1}$, L. Morales-Rivas ${ }^{3}$ and F.G. \\ Caballero $^{3}$ \\ ${ }^{1}$ Materials Science and Engineering, Ohio State University, Columbus, Ohio 43221, USA \\ ${ }^{2}$ Los Alamos National Laboratory, Lujan Center (LANSCE-LC), P.O. Box 1663, Los \\ Alamos, NM 87545, USA \\ ${ }^{3}$ Department of Physical Metallurgy, Centro Nacional de Investigaciones Metalúrgicas \\ (CENIM-CSIC), Avda. Gregorio del Amo, 8. E-28040 Madrid, Spain
}

Keywords: bainitic steels, TRIP effect, Neutron diffraction

\begin{abstract}
.-
In situ neutron diffraction experiment was used during tensile testing at room temperature to examine the changes on the percentage and texture of both ferrite and austenite in a nanocrystalline bainitic steels transformed at two different temperatures $200^{\circ} \mathrm{C}$ and $300^{\circ} \mathrm{C}$ for different times to achieve the same phase percentages. Both samples showed an inadequate capability of austenite to transform to martensite under strain to take full advantage of the transformation-induced plasticity effect.

A new generation of nanocrystalline steels relies on a bainitic microstructure formed at low temperature that contains plate-like ferrite and a significant volume percentage of retained austenite. This retained austenite may transform into martensite during the course of deformation [1]. This stress- or strain-induced transformation leads to additional plasticity, which enables ultra-high strength steels typically above $2 \mathrm{GPa}$, an increase in the workhardening rate during plastic deformation, as well as, an increase in uniform elongation by delaying necking [2]. However, if the initial extent of the austenitic to bainitic transformation is small, the uniform elongation will be poor despite the retention of a large volume fraction of austenite. This is because the austenite is found to occur in two forms: (i) micron/sub-micron blocks of retained austenite located between the sheaves of bainite and (ii) as nano-scale films of austenite which are retained between the subunits within a given sheaf of bainite [3]. There is ample evidence that the larger retained austenite, which is less enriched in carbon [4], can decompose to martensite even at relatively small plastic strains [3]. The stability of the austenite is, therefore, critical in obtaining good ductility in nanocrystalline bainitic steels.

The good uniform elongation properties of transformation-induced plasticity (TRIP) assisted steels are mainly due to the composite deformation behavior of austenite, ferrite and martensite phases with different constitutive properties [5]. When a composite microstructure is stressed, the plastic strain is at first focused in the more ductile soft phase, which work-hardens [6,7]. Eventually, the harder phase also deforms plastically. Ryu et al. [8] experimentally demonstrated that the partitioning of strain between phases can
\end{abstract}


dramatically influence the mechanically stability of austenite in TRIP steels. Austenite, which is harder than the ferrite, begins to deform after ferrite has work hardened, experiencing less deformation than the average elongation recorded on the tensile specimen.

Other alternative effects of retained austenite on ductility discussed in literature are the blocking micro-crack propagation effect [9], related to the high deformation strengthening ability of the austenite that improves the resistance to slip $[10,11]$ and the possibility of retained austenite acting as a sink for the dislocations from neighbouring martensite laths that may also allow the martensite phase to deform further.

In recent years, in situ neutron and/or high-energy X-ray diffraction experiments have led to new insights into the deformation behavior of low-alloyed TRIP steels [12-17]. However, due to the composite-like microstructure and the complex deformation/transformation behavior in these materials, the reported neutron and synchrotron experiments were designed to focus on the stress partitioning between the constituent phases. The aim of the present paper is to assess in situ the changes induced by the applied tensile stress on the phase fraction and texture of both bainitic ferrite and austenite in a nanocrystalline bainitic steel. For that purpose, two samples transformed at two different temperatures $\left(200^{\circ} \mathrm{C}\right.$ and $\left.300^{\circ} \mathrm{C}\right)$, but containing the same (35\%) austenite percentages were studied by performing in situ neutron diffraction (ND) during deformation. The characteristics of each phase (amount and texture) were analyzed as a function of the plastic strain.

The steel, with the approximate composition of Fe-0.8C-1.5Si-2Mn-1Cr-0.2Mo-1.5Co$1 \mathrm{Al}$ (wt.\%), was supplied as a homogenized ingot. The details of the alloy preparation have been presented elsewhere [18]. Two specimens were austenitized for $30 \mathrm{~min}$ at $900^{\circ} \mathrm{C}$ and then isothermally transformed at $200^{\circ} \mathrm{C}$ and $300^{\circ} \mathrm{C}$ for different times to reach the same degree of bainite transformation (65\%) before quenching into water. Quantitative X-ray diffraction (XRD) analysis was used for determining the volume fraction of retained austenite. Moreover, austenite and ferrite carbon content was calculated from the measured lattice parameters [4].

Texture analysis was completed using ND on the HIPPO (high-pressure preferred orientation) instrument at Los Alamos Neutron Science Center (LANSCE) of Los Alamos National Laboratories (LANL). This instrument uses the neutron time-of-flight technique, i.e., it collects diffraction spectra at several detectors using a white neutron beam (within the wavelength range $0.5-4.5 \AA$ ). The angular detector coverage is very large, and only four exposures at different sample rotations are necessary to collect a large number of pole figures, enabling the ability to reconstruct an orientation distribution function (ODF). The diffraction spectra were refined using the Rietveld method [19] and the pole figures were generated.

In situ ND tensile tests were carried out on the spectrometer for materials research at temperature and stress (SMARTS) instrument at LANSCE. Two detectors, located at $\pm 90^{\circ}$ from the incident beam, are available, and the wavelength range extends from 0.4 to $3.8 \AA$. An Instron test rig, equipped with a load cell of $10 \mathrm{kN}$ with two tailored steel plates, was mounted on the sample stage of the instrument. Tensile stress was applied in a step-by-step manner and ND profiles were recorded during temporary stops of the crosshead as Fig. 1 illustrates.

Transmission electron microscopy (TEM) images of the resultant microstructures, consisting of nano-scale plates of bainitic ferrite $(45-50 \mathrm{~nm})$, separated by carbon-enriched 
regions of retained austenite, are shown elsewhere [3]. The volume percentage of the austenite was determined by XRD to be 35\% in both samples. However, the XRD data listed in Table 1 indicated that although the same percentage of bainitic ferrite was formed (65\%) at both temperatures, the austenite was not similarly enriched in carbon. In fact, the measured carbon content of the austenite at $200^{\circ} \mathrm{C}$ demonstrates that carbon fails to partition into the residual austenite [20]. The XRD data in Table 1 also indicate a comparable carbon content of the ferrite after transformation at $200^{\circ} \mathrm{C}$ and $300^{\circ} \mathrm{C}$, and in both samples, is well above that expected from paraequilibrium (PE) with austenite $(\sim 0.03$ wt.\%). This behaviour is attributed to the trapping of carbon at crystal defects such as dislocations, twin boundaries and interfaces [21], and also to a large fraction of carbon in solid solution within the ferrite [22], both events confirmed by atom probe tomography.

Macroscopic tensile stress-strain curves in Fig. 1 showed that the microstructure obtained by transformation at $300^{\circ} \mathrm{C}$ exhibited an uniform elongation of $\sim 10 \%$, higher than that at $200^{\circ} \mathrm{C}$, where the elongation is reduced to $2 \%$. In this case all the elongation was uniform and hardly any necking was observed in the tested samples. The larger true uniform strains of the specimen treated at $300^{\circ} \mathrm{C}$ was found to be due to a continuous increase (up to 0.15 ) in the incremental work-hardening coefficient after a decrease (down to 0.05) at low plastic strains [3]. By contrast, for the microstructure obtained at $200^{\circ} \mathrm{C}$, the incremental workhardening coefficient displayed a continuous increase (up to 0.1) towards the instability criteria, which is never reached, explaining the fact that all the measured elongation is uniform [3].

The ND data are presented by showing the volume fraction of the constituent phases distinguishable in the diffraction patterns recorded during the different temporary stops of the crosshead, i.e. austenite (FCC) and ferrite (BCC). Additionally, the martensitic BCT reflections stemming from the newly formed and suitably oriented martensite phase are partially or completely overlapped with bainitic ferrite reflections, making their analysis virtually impossible [15]. Thus, only two phases were considered in the current analysis of the ND data: the ferrite matrix (bainitic ferrite and martensite in the plastic region) and austenite. Interpretation of the ferrite matrix results must, therefore, be done cautiously due to possible overlap with martensite.

The evolutions of the austenite fraction as a function of deformation for the two bainitic microstructures are shown in Fig. 2a. The austenite fraction in the sample transformed at $200^{\circ} \mathrm{C}$ showed a significant reduction during the very early stage of deformation, from $\sim 30 \%$ at $0 \%$ deformation to $15 \%$ at $2 \%$ deformation. At $3 \%$ deformation, the sample broke. On the contrary, no evidence of austenite to martensite transformation was observed before necking ( $10 \%$ deformation) in the sample treated at $300^{\circ} \mathrm{C}$. Beside the normal differences between ND and XRD values for the retained austenite percentage [23] in the initial microstructures (a difference of $2 \%$ for the $300^{\circ} \mathrm{C}$ sample and $6 \%$ for the $200^{\circ} \mathrm{C}$ sample), the martensite formation in both specimens with similar contents of retained austenite showed a different trend. Transformation was exhausted at small plastic strains in the sample treated at $200^{\circ} \mathrm{C}$ losing the protection against necking instability. It seems that transformation could take place during the elastic loading condition by stress-induced transformation, probably due to its lower austenite carbon content and the favorable crystallographic orientation of austenite grains with respect to the applied stress direction. As a result, on increasing the stress, above $2 \mathrm{GPa}$, the austenite transforms to martensite leading to rapid strain hardening. Quite the opposite, the austenite was too stable in the 
sample treated at $300^{\circ} \mathrm{C}$ without contributing to strain hardening. The rather unexpected result is the extremely high mechanical stability of austenite detected in the specimen transformed at $300^{\circ} \mathrm{C}$. As a result, the majority of the austenite remained untransformed in the necked region, which avoids taking full advantage of its beneficial effect on ductility. In contradiction to published results of the hardness of retained austenite and ferrite in conventional TRIP-assisted steels [24], Lan et al [25] showed that the nanohardness of the thin bainite platelets in the nanostructured steel exceeds that of retained austenite as a result of the fine scale of the plates and second the excess carbon that they contain, when compared against conventional bainite generated at higher temperatures. In addition, bainitic ferrite that formed at $200^{\circ} \mathrm{C}$ is expected to be stronger than that formed at $300^{\circ} \mathrm{C}$ as a consequence of the finer plate thickness and the higher amount of crystal defects [2]. On the other hand, the carbon content in austenite, not only controls its ability to transform into martensite under loading, but also its strength. In this sense, the strength mismatch between both phases (bainitic ferrite and austenite) may explain the differences on mechanical behaviour observed in both samples.

Apart from the mechanically induced martensitic transformation of the meta-stable austenite grains, the constituent austenite grains of the microstructure reacts to the applied stress by undergoing physical rotations in space with reference to the sample axis. The resultant texture evolution would have an appreciable effect on the elastic and plastic anisotropy of the polycrystalline (austenite, martensite and bainitic ferrite) aggregate, and also on the critical stress to trigger the martensitic transformation in the remaining austenite. Consequently the question arises as to whether there will be any difference in the texture due to stress induced transformation in the sample transformed at $200^{\circ} \mathrm{C}$ and due to plastic deformation in the sample transformed at $300^{\circ} \mathrm{C}$.

The comparison of the texture, in terms of the minimum and maximum intensity of the orientation distribution function (ODF) as a function of strain is shown in Fig. 2b. Likewise, the changes in texture during deformation at room temperature are displayed in Figs. 3 and 4 for the samples transformed at $200^{\circ} \mathrm{C}$ and $300^{\circ} \mathrm{C}$, respectively, for selected strain levels. The starting texture state for both samples corresponds to a mainly random distribution of the grains in both the ferritic matrix and the retained austenite. The texture changes consistently with tensile deformation of BCC and FCC materials. As plastic strain increases the grains in both phases are undergoing significant rotations, so that the BCC (110) and the FCC (111) deformation components gradually become dominant.

However, Fig. 2b clearly suggests that at $\%$ of plastic strain, the FCC texture in the sample transformed at $200^{\circ} \mathrm{C}(\mathrm{HT}-200)$ becomes stronger than that in the sample transformed at $300^{\circ} \mathrm{C}$ (HT-300), which reaches that level of intensity of ODF only after a plastic strain of $\sim 8 \%$ as shown in Figs. 2b and 4. The FCC texture in HT-200 sample strengthens rapidly along the tensile axes as the centre of the (111) component indicates in Fig. 3. It is clear that the (111) planes perpendicular to the tensile axes are not favourably oriented for the stress induced martensite transformation. This is supported by the rapid reduction in austenite fraction shown in Fig. 2a. On the other hand, the FCC texture strengthens slowly along the tensile axes in the sample transformed at $300^{\circ} \mathrm{C}$ as shown in Fig. 4.

At the same time, BCC texture in the sample transformed at $300^{\circ} \mathrm{C}$ slightly change after loading suggesting that the ferrite is able to deform to certain extension under tension. This analysis is virtually impossible in the HT-200 sample due to the overlapping of BCT reflections from the newly formed martensite. But, consistently with a stronger bainitic 
ferrite matrix, the minimal BCC texture change detected in this sample suggests that ferrite hardly deforms under tension.

In summary, the rapid strain hardening during tensile testing of bainite formed at $200^{\circ} \mathrm{C}$ is related to the reduction of austenite fraction due to stress induced transformation. The critical resolved shear stress needed to induce the martensitic transformation is achieved due to strong bainitic ferrite, leading to premature failure. On the contrary, in samples heat treated at $300^{\circ} \mathrm{C}$, both bainitic ferrite and austenite are capable to deform allowing for a larger elongation. The strength mismatch between both phases (bainitic ferrite and austenite) may explain the differences on mechanical behaviour observed in both samples. In view of the strong correlation between the complex composite structure and deformation behaviour of nanostructured bainitic steels, a great effort should be made to determine the local structural characteristics of austenite and their surrounding nano-scale matrix and how their individual mechanical response affect the stability of the embedded austenite grains.

In this sense, advanced nanoindentation techniques such as peak force tapping on scanning probe microscopy (SPM) are required to confirm all these assumptions. This investigation is in progress.

\section{Acknowledgement}

The authors gratefully acknowledge the support of the Spanish Ministry of Science and Innovation for funding this research under the contract MAT2010-15330, respectively. L. Morales-Rivas also acknowledges the Spanish Ministry of Science and Innovation for financial support in the form of a PhD research grant (FPI).

\section{References}

1. F.G. Caballero, H.K.D.H Bhadeshia, Curr. Opin. Solid State and Mater. Sci. 8 (2004) 251.

2. C. Garcia-Mateo, F.G. Caballero, ISIJ Inter. 45 (2005) 1736.

3. C. Garcia-Mateo, F.G. Caballero, Mater. T. JIM 46 (2005) 1839.

4. C. Garcia-Mateo, F.G. Caballero, M.K. Miller, J.A. Jimenez, J. Mater. Sci. 47 (2012) 1004.

5. H.K.D.H Bhadeshia, ISIJ Inter. 42 (2002) 1059.

6. Y. Tomota, K. Kuroki, T. Mori, I. Tamura, Mater. Sci. Eng A 24 (1976) 85.

7. H.K.D.H. Bhadeshia, D.V. Edmonds, Met. Sci. 14 (1980) 41.

8. J.H. Ryu, D-I. Kim, H.S. Kim, H.K.D.H Bhadeshia, D-W. Suh, Scripta Mater. 63 (2010) 297.

9. C.G. Lee, S-J. Kim, T-H. Lee, S. Lee, Mater. Sci. Eng. A 371 (2004) 16.

10. L. Wenyan, Q. Jingxin, S. Hesheng, J. Mater. Sci. 32 (1997) 427.

11. K. Zhang, M. Zhang, Z. Guo, N. Chen, Y. Rong, Mater. Sci. Eng. A 528 (2011) 8486. 
12. P.J. Jacques, Q. Furnemont, S. Godet, T. Pardoen, K. Conlon, F. Delannay, Phil. Mag. 86 (2006) 2371.

13. K.S. Choi, W.N. Liu, X. Sun, M.A. Khaleel, Y. Ren, Y.D. Wang, Metall. Mater. Trans. A 39 (2008) 3089.

14. S. Cheng, X.L. Wang, Z. Feng, B. Clausen, H. Choo, P.K. Liaw, Metall. Mater. Trans. A 39 (2008) 3105.

15. O. Muránsky, P. Sittner, J. Zrník, E.C. Oliver, Acta Mater. 56 (2008) 3367.

16. N. Jia, Z.H. Cong, X. Sun, S. Cheng, Z.H. Nie, Y. Ren, P.K. Liaw, Y.D. Wang, Acta Mater. 57 (2009) 3965.

17. S. Cheng, Y.D. Wang, H. Choo, X-L. Wang, J.D. Almer, P.K. Liaw, Y.K. Lee, Acta Mater. 58 (2010) 2419.

18. C. Garcia-Mateo, F.G. Caballero, H.K.D.H. Bhadeshia, ISIJ Inter. 43 (2003) 1821.

19. H.M. Rietveld, J. Appl. Cryst. 2 (1968) 65.

20. P.G. Winchell, M. Cohen, Trans. ASM 55 (1962) 347.

21. F.G. Caballero, M.K. Miller, S.S. Babu, C. Garcia-Mateo, Acta Mater. 55 (2007) 381.

22. F.G. Caballero, M.K. Miller, C. Garcia-Mateo, J. Cornide, M.J. Santofimia, Scripta Mater. 67 (2012) 846.

23. J. Zrnik, O. Muransky, P. Lukas, Z. Novy, P. Sittner, P Hornak, Mater. Sci. Eng. A 437 (2006) 114.

24. Q. Furnemont, M. Kempf, P.J. Jacques, M. Göken, F. Delannay, Mater. Sci. Eng. A 328 (2002) 26.

25. H.F. Lan, X.H. Liu, L.X. Du, Adv. Mater. Res. 156-157 (2011) 1708. 


\section{Table Caption}

Table 1: Volume fraction (V) and carbon content (C) in ferrite $(\alpha)$ and austenite $(\gamma)$ determined by XRD analysis. 


\section{Figure Captions}

Figure 1.- Macroscopic tensile stress-strain curve of samples transformed to bainite at $300^{\circ} \mathrm{C}$ and $200^{\circ} \mathrm{C}$. The lines indicate unloads for crystallographic texture measurements.

Figure 2.- (a) Evolution of the austenite percentage and (b) Orientation Distribution Function (ODF) in both ferrite and austenite phases as a function of plastic strain in the samples transformed at $200{ }^{\circ} \mathrm{C}(\mathrm{HT}-200)$ and $300^{\circ} \mathrm{C}(\mathrm{HT}-300)$.

Figure 3.- Texture evolution in both ferrite and austenite phases in the sample transformed at $200{ }^{\circ} \mathrm{C}$ for selected deformation steps.

Figure 4.- Texture evolution in both ferrite and austenite phases in the sample transformed at $300{ }^{\circ} \mathrm{C}$ for selected deformation steps. 


\section{Figure Captions}

Figure 1.- Macroscopic tensile stress-strain curve of samples transformed to bainite at $300^{\circ} \mathrm{C}$ and $200^{\circ} \mathrm{C}$. The lines indicate unloads for crystallographic texture measurements.

Figure 2.- (a) Evolution of the austenite percentage and (b) Orientation Distribution Function (ODF) in both ferrite and austenite phases as a function of plastic strain in the samples transformed at $200^{\circ} \mathrm{C}(\mathrm{HT}-200)$ and $300^{\circ} \mathrm{C}(\mathrm{HT}-300)$.

Figure 3.- Texture evolution in both ferrite and austenite phases in the sample transformed at $200{ }^{\circ} \mathrm{C}$ for selected deformation steps.

Figure 4.- Texture evolution in both ferrite and austenite phases in the sample transformed at $300{ }^{\circ} \mathrm{C}$ for selected deformation steps. 
Table 1: Volume fraction (V) and carbon content (C) in ferrite $(\alpha)$ and austenite $(\gamma)$ determined by XRD analysis.

\begin{tabular}{lllll}
\hline Heat Treatment & $\mathrm{V}_{\alpha}$ & $\mathrm{V}_{\gamma}$ & $\mathrm{C}_{\alpha}, \mathrm{wt} . \%$ & $\mathrm{C}_{\gamma}$, wt.\% \\
\hline $200^{\circ} \mathrm{C}-3$ days & $0.65 \pm 0.03$ & $0.35 \pm 0.03$ & $0.21 \pm 0.08$ & $0.67 \pm 0.08$ \\
$300^{\circ} \mathrm{C}-6$ hours & $0.65 \pm 0.02$ & $0.35 \pm 0.03$ & $0.17 \pm 0.08$ & $1.33 \pm 0.08$ \\
\hline
\end{tabular}




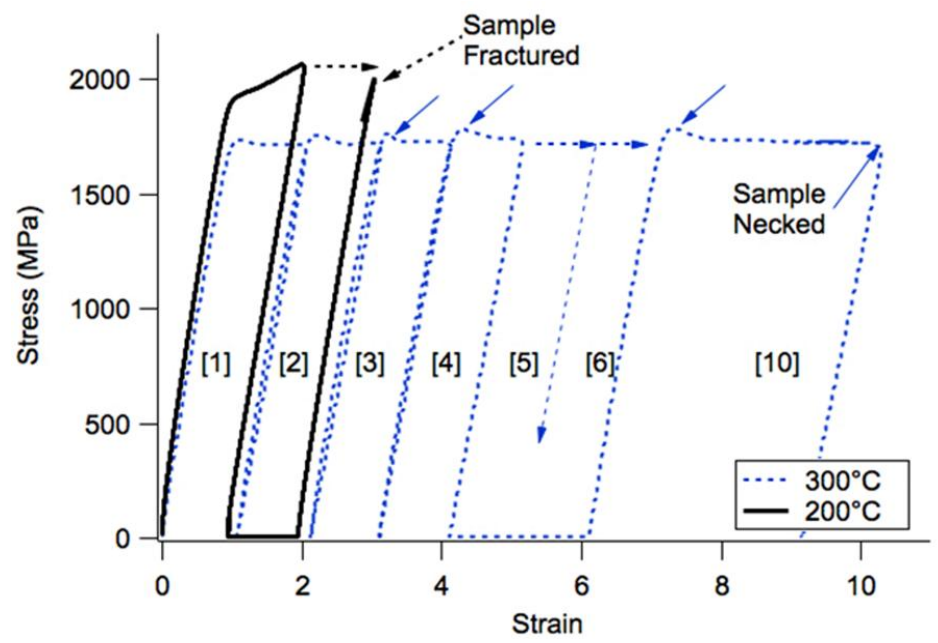

Figure 1.- Macroscopic tensile stress-strain curve of samples transformed to bainite at $300^{\circ} \mathrm{C}$ and $200^{\circ} \mathrm{C}$. The lines indicate unloads for crystallographic texture measurements. 

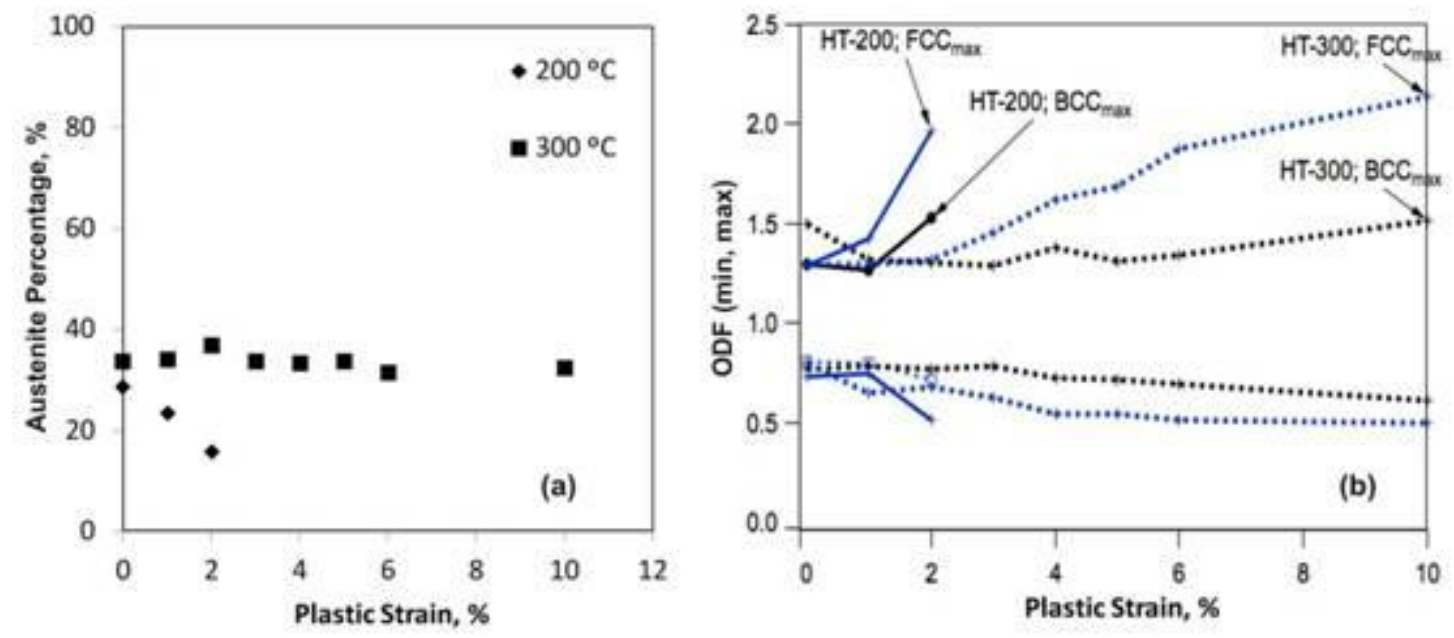

Figure 2.- (a) Evolution of the austenite percentage and (b) Orientation Distribution Function (ODF) in both ferrite and austenite phases as a function of plastic strain in the samples transformed at $200{ }^{\circ} \mathrm{C}$ (HT-200) and $300^{\circ} \mathrm{C}$ (HT-300). 


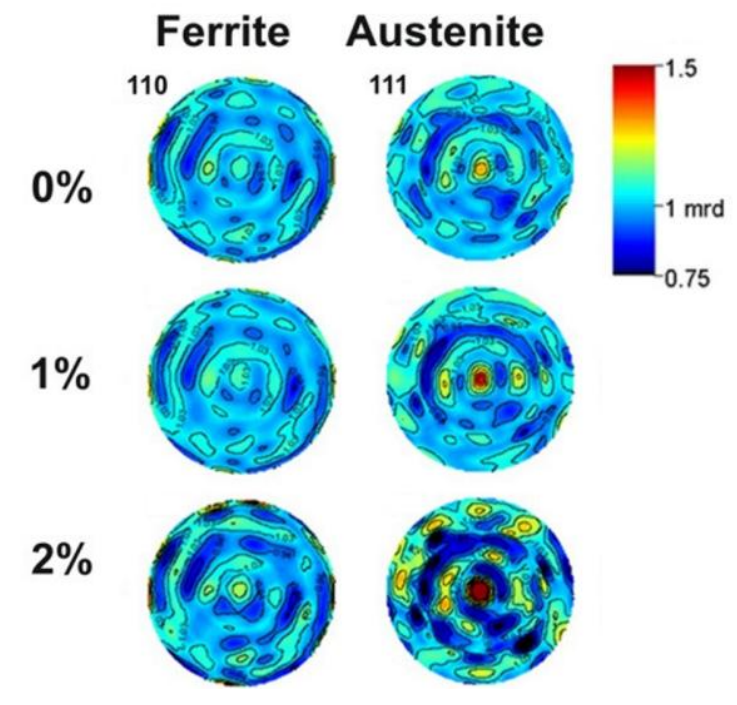

Figure 3.- Texture evolution in both ferrite and austenite phases in the sample transformed at $200{ }^{\circ} \mathrm{C}$ for selected deformation steps. 


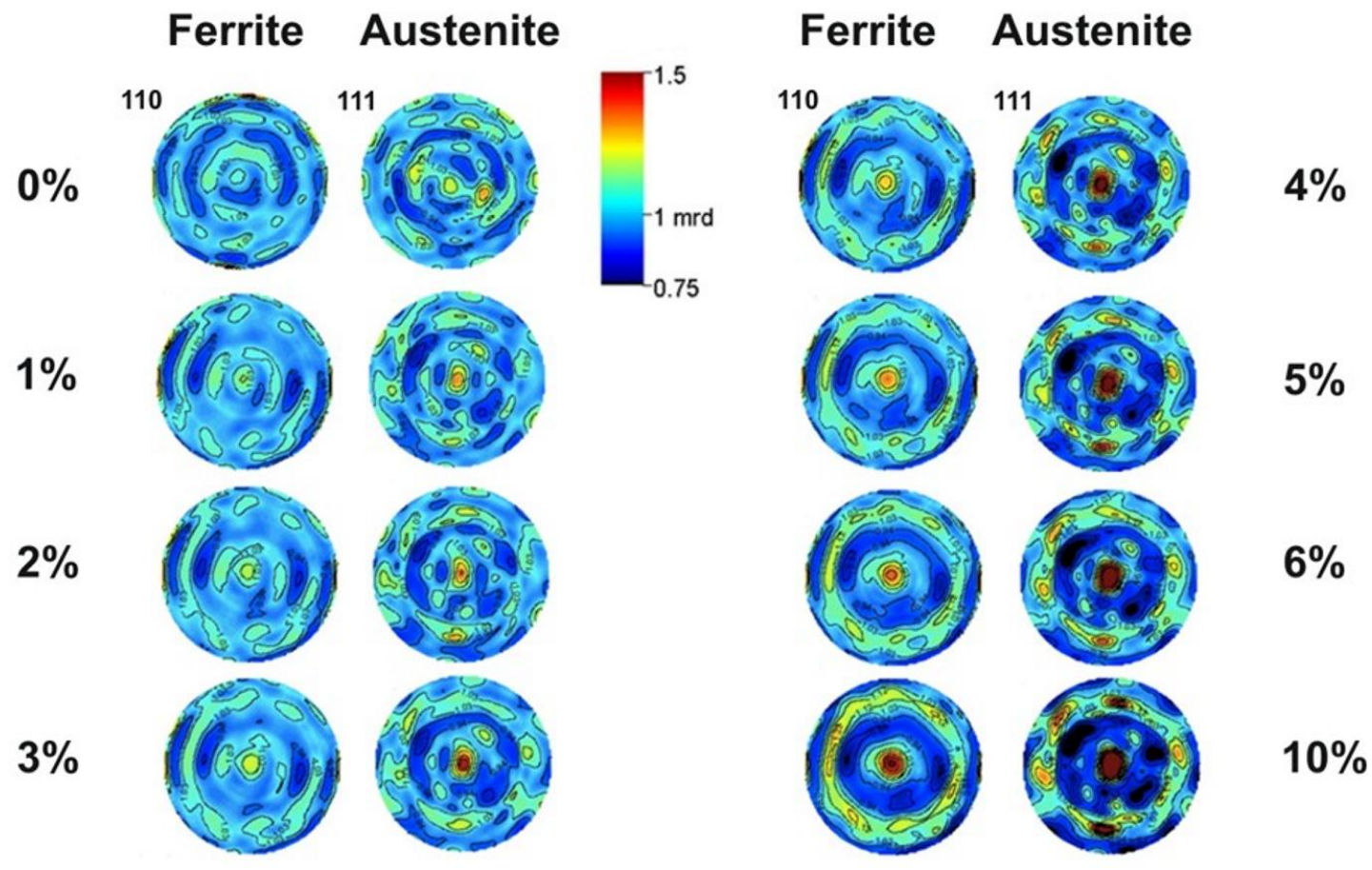

Figure 4.- Texture evolution in both ferrite and austenite phases in the sample transformed at $300{ }^{\circ} \mathrm{C}$ for selected deformation steps. 


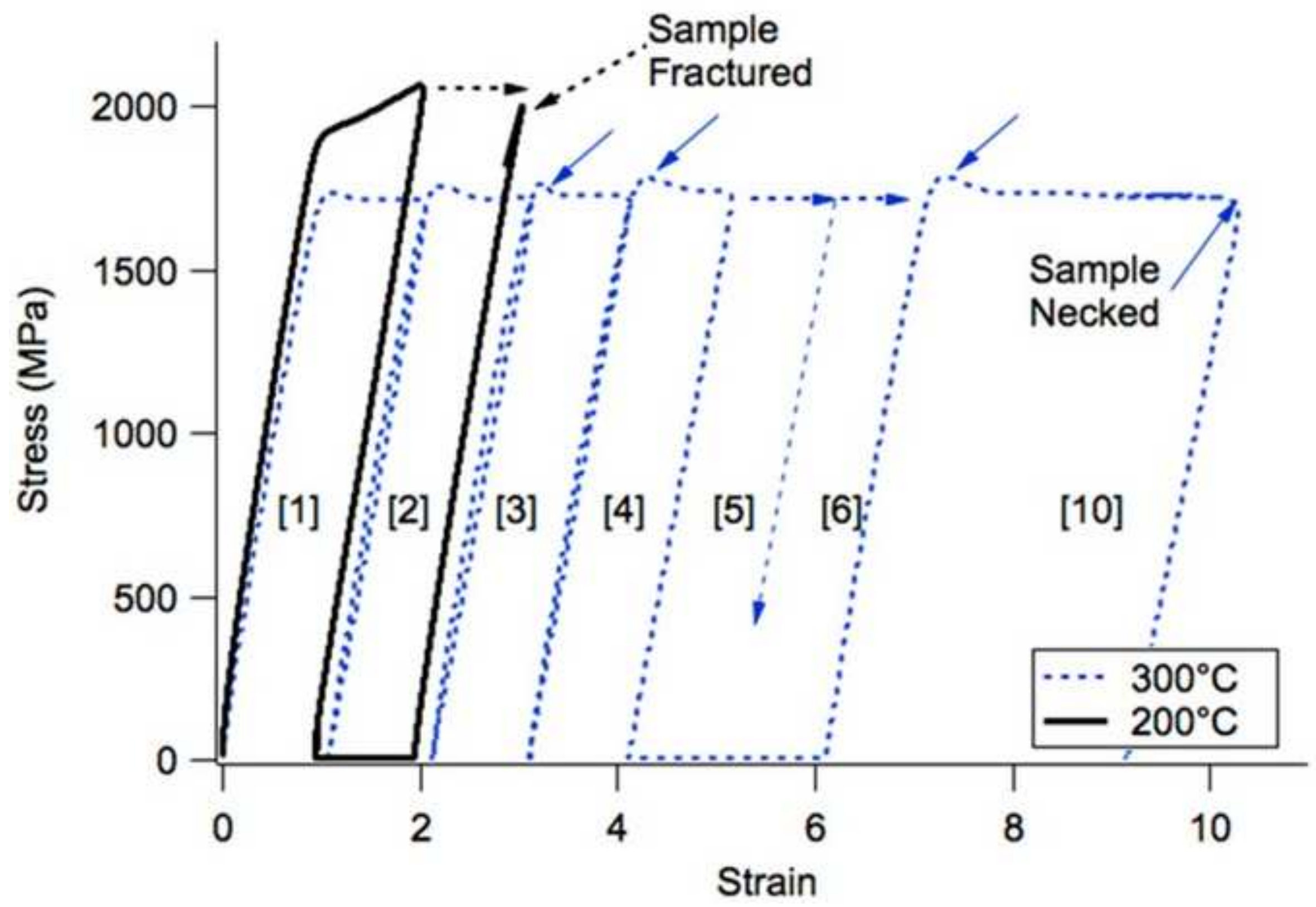



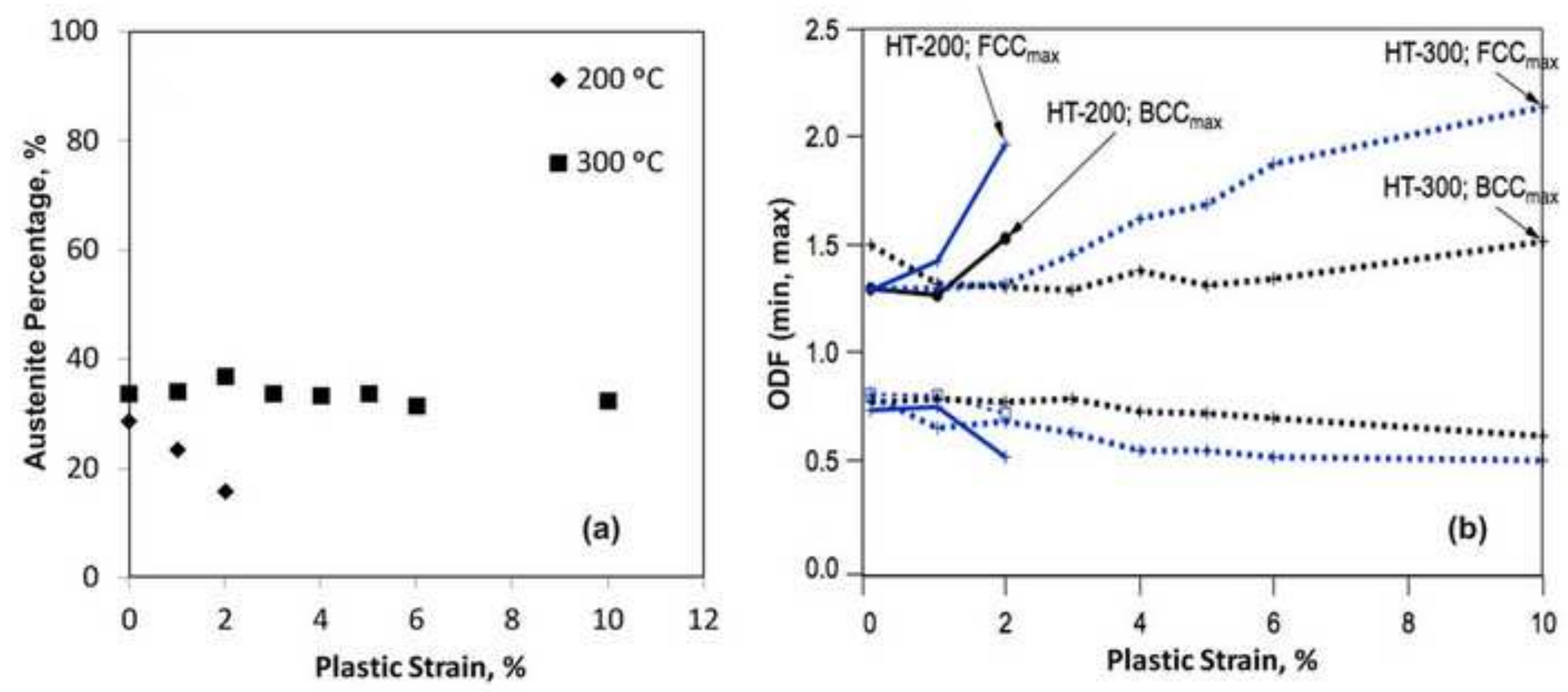


\section{Ferrite Austenite}

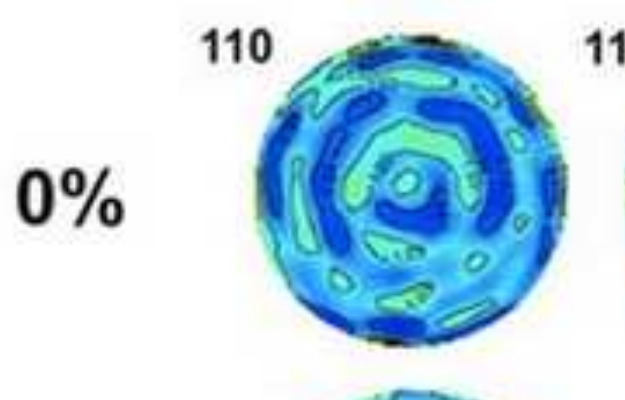

$1 \%$

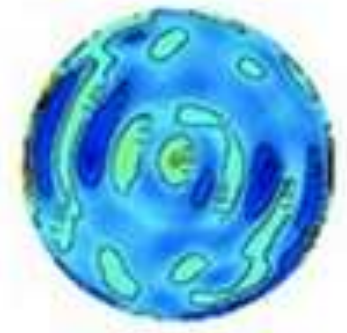

$2 \%$

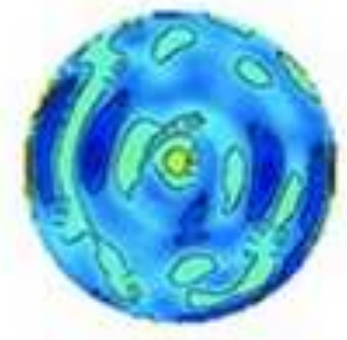

$3 \%$

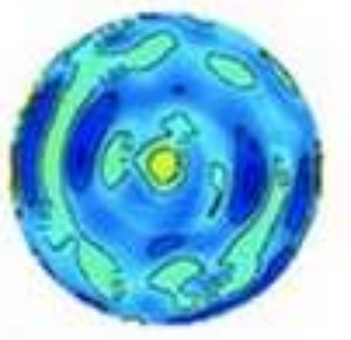

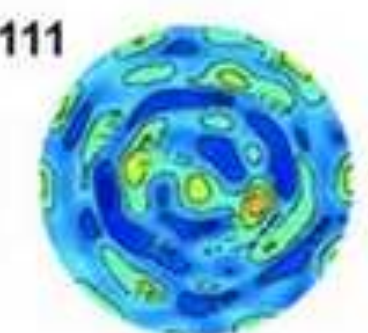
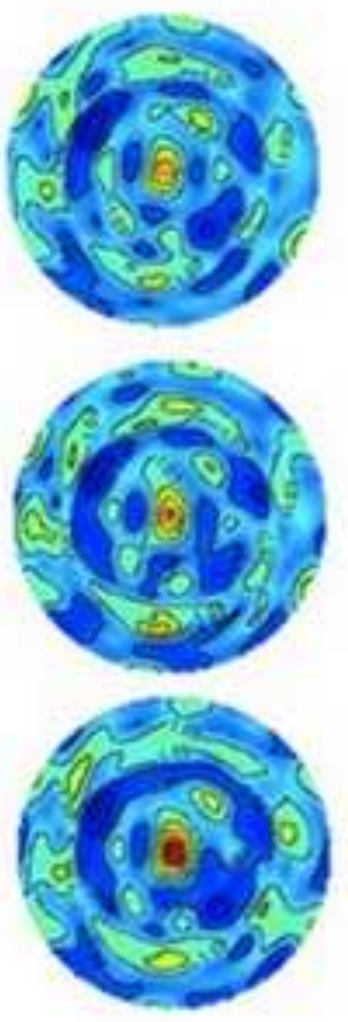

\section{Ferrite Austenite}
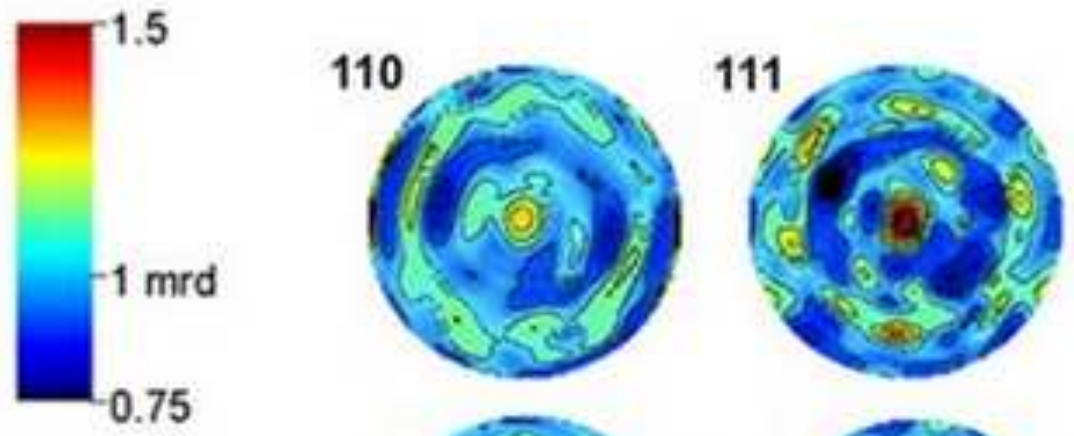

$4 \%$
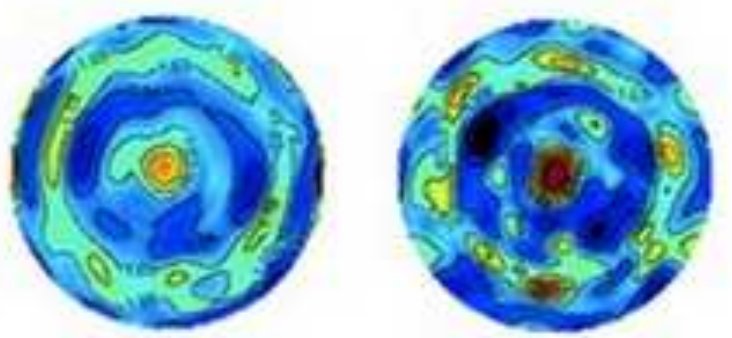

$5 \%$
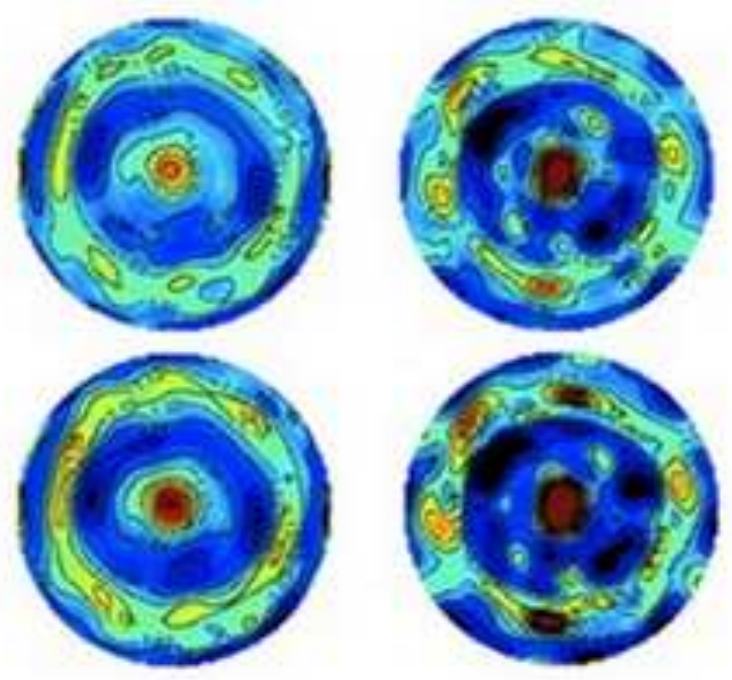